\title{
Clinical Signs and Symptoms and Laboratory Findings of Methadone Poisoning in Children
}

\author{
Mohammad Reza Sharif ${ }^{1}$; Saeed Nouri ${ }^{2, *}$ \\ ${ }^{1}$ Trauma Research Center, Kashan University of Medical Sciences, Kashan, IR Iran \\ ${ }^{2}$ Chemical Injuries Research Center, Baqiyatallah University of Medical Sciences, Tehran, IR Iran \\ *Corresponding author: Saeed Nouri, Chemical Injuries Research Center, Baqiyatallah University of Medical Sciences, Tehran, IR Iran. Tel: +98-9131365741, E-mail: snouri1987@yahoo. \\ com
}

Received: March 8, 2014; Accepted: November 16, 2014

\begin{abstract}
Background: Poisoning accounts for about 7\% of all accidents in children under 5 years and is implicated in over $5 \%$ of all childhood deaths in developing countries.

Objectives: Due to the potential risks of methadone poisoning in children and increased cases of methadone poisoning among Iranian children, this study was conducted to investigate the clinical signs and symptoms and laboratory findings of methadone toxicity in children.

Patients and Methods: The present retrospective, descriptive, cross-sectional study describes the clinical symptoms and signs and laboratory findings of methadone poisoning in children under 12 years old in Shahid Beheshti Hospital, Kashan, during the years 2009 to 2013.

Results: Of 58 patients, $33(56.9 \%)$ were male and $25(43.1 \%)$ female $(P=0.294)$. The mean age of patients was $5.2 \pm 1.0$ years. All the cases of poisoning happened with methadone syrup, due to unsafe keeping of methadone in mineral water bottles and containers of other drugs. Signs and symptoms included drowsiness (91.4\%), miosis (75.9\%), vomiting (69.0\%), ineffective breathing (any kind of breathing problem except apnea) (62.1\%), apnea (53.4\%), cyanosis (43.1\%), seizure (8.6\%), ataxia (6.9\%) and delirium (3.4\%).

Conclusions: Keeping methadone in appropriate containers and warning methadone consumers about the dangerous side effects of its consumption and the symptoms of methadone poisoning in children may minimize the occurrence of this form of poisoning and its complications in children.
\end{abstract}

Keywords: Poisoning; Methadone; Child

\section{Background}

Poisoning accounts for about $7 \%$ of all accidents in children under 5 years and is implicated in about $2 \%$ of all childhood deaths in the developed world, and over $5 \%$ in developing countries (1-3). Toxicity by opium or its derivatives is one of the most common forms of child poisoning which is very dangerous, and can lead to loss of consciousness, respiratory suppression, apnea, coma and eventually death $(4,5)$. Evidence has shown that the incidence of poisoning with opium and its derivatives is growing (6-11). The pattern of poisoning in children is constantly changing, and every day we face new, unknown and dangerous compounds (5). Methadone (Dolophine) is a synthetic opioid with a long half-life $(5,12)$. In recent years methadone syrup and tablets are commonly used in Iran for relieving pain and treating addiction. Methadone syrup containing five milligram methadone per each milliliter and consuming one milligram of methadone per each kilogram of the child's weight could be fatal (13). Methadone syrup is a bright amber colored liquid, and most parents keep this liquid in the bottles of mineral water in refrigerators, and this unsafe keep- ing leads to methadone poisoning in children (14). Symptoms of the methadone poisoning include nausea, lethargy, sleepiness, apnea and even death. Other side effects of methadone consumption in children are cardiac signs such as increased QT interval (15-18). It should be considered that the information given in pamphlets about the signs and symptoms, diagnosis and treatment of methadone poisoning refers to adults and people with chronic drug abuse, and the overdose of methadone in children is under-investigated. Few studies have been conducted to determine the clinical symptoms and signs of methadone poisoning in children $(13,19-24)$.

\section{Objectives}

Due to the potential risks of methadone poisoning and increased cases of methadone poisoning in children, this study was performed to investigate the causes, signs and symptoms of methadone toxicity in children. The results of this study and similar studies can provide a practical approach to determine the causes and clinical course of methadone poisoning in children.

Copyright (C) 2015, Growth \& Development Research Center. This is an open-access article distributed under the terms of the Creative Commons Attribution-NonCommercial 4.0 International License (http://creativecommons.org/licenses/by-nc/4.0/) which permits copy and redistribute the material just in noncommercial usages, provided the original work is properly cited. 


\section{Patients and Methods}

This retrospective, descriptive, cross-sectional study was carried out at pediatric intensive care unit of Shahid Beheshti Hospital in Kashan, a city located in the center of Iran, with a population of 400,000 people. Information about methadone poisoning in children under 12 years, from 2009 to 2013, was collected from the medical records provided by hospital doctors and interns. All suspected poisonings were initially included, but patients were excluded from the study if the initial diagnosis of methadone poisoning was rejected, clinically or otherwise. The information obtained from the conscious patients or their relatives was the basis of diagnosis of intoxication with methadone or co-ingested compounds. The inclusion criteria were age below 12 years, and a diagnosis of methadone toxicity based on history and practitioners' judgment. Cases that were not confirmed to be methadone poisoning and children, who used other substances in addition to methadone, were excluded from the study. The information about each case was recorded in standardized forms. The data included demographic information, clinical signs and symptoms, laboratory findings, and how children had access to methadone. Medical terms such as increased or decreased heart rate was defined according to Nelson Textbook of Pediatrics (25). Finally, the obtained data was entered into the Statistical Package for the Social Sciences (SPSS) software, version 16.0 (SPSS, Inc., Chicago, IL, USA). Quantitative variables were shown as the mean and standard deviation, while qualitative variables were expressed as frequencies and percentages. Subgroup analyses were performed using chi-square tests.

\section{Results}

Fifty eight patients were admitted to Shahid Beheshti Hospital, Kashan, due to methadone poisoning during the period of four years, from 2009 to 2013.

\subsection{Age and Sex}

The mean age of patients was $5.2 \pm 1.0$ years with the minimum age of 3 months and maximum of 12 years. Of 58 patients $33(56.9 \%)$ were male and 25 (43.1\%) female.

\subsection{Route of Exposure}

All the cases of poisoning had happened with the syrup form of methadone due to unsafe holding of methadone in bottles of mineral water or other medications. 87.9\% of children had inadvertently used methadone themselves, and in $12.1 \%$ of patients, parents fed them methadone by mistake.

\subsection{Amount of Methadone Ingestion}

In most cases it is impossible to determine the exact amount of methadone ingestion, and when the container is available, the amount of methadone can only be es- timated. In this study, the information about the amount of methadone intake has been estimated based on the parents' report. Accordingly, the least amount of intake was $10 \mathrm{mg}$ and the highest was $100 \mathrm{mg}$, with the average methadone consumption of $30 \pm 18.2 \mathrm{mg}$.

\subsection{Onset of Symptoms}

The interval between methadone consumption and the onset of symptoms ranged from 90 to 150 minutes. On average, $120 \pm 15.2$ minutes after consuming methadone, the patients' symptoms started to appear.

\subsection{Signs and Symptoms}

The majority (91.4\%) of children with methadone poisoning suffered from drowsiness and loss of consciousness. Miosis, vomiting and ineffective breathing (any kind of breathing problem except apnea) were other most common signs and symptoms, $75.9 \%, 69 \%$ and $62.1 \%$, respectively (Table 1$)$. Twenty eight $(48.3 \%)$ patients had respiratory infection (pneumonia) in the course of their hospitalization. There was a significant direct relationship between the amount of methadone consumption and the incidence of apnea in children $(P=0.000) .15 .5 \%$ of children had hypotension. None of the children had any change in body temperature (neither high nor low) at the time of admission; while their heart rates were variable; $5.2 \%$ of children had increased heart rate while $10.3 \%$ had decreased heart rate. The classic triad of methadone poisoning in adults, loss of consciousness (somnolence), ineffective respiration and miosis, were observed in $53 \%$ of the children.

Table 1. The Frequency of Clinical Signs and Symptoms in Children With Methadone Poisoning ${ }^{\mathrm{a}}$

\begin{tabular}{lc}
\hline Clinical Signs or Symptoms & \\
\hline Drowsiness & $53(91.4)$ \\
\hline Miosis & $44(75.9)$ \\
\hline Vomiting & $40(69.0)$ \\
\hline $\begin{array}{l}\text { Ineffective breath( any kind of } \\
\text { breathing problem except apnea) }\end{array}$ & $36(62.1)$ \\
\hline Apnea & $31(53.4)$ \\
\hline Cyanosis & $25(43.1)$ \\
\hline Seizure & $5(8.6)$ \\
\hline Ataxia & $4(6.9)$ \\
\hline Delirium & $2(3.4)$ \\
\hline
\end{tabular}

a Data are presented as No. (\%).

\subsection{Paraclinical Findings}

Respiratory acidosis was the most (73\%) common laboratory finding in patients, and leukocytosis was observed in less than half (46\%) of the patients. Only $14 \%$ of the pa- 
tients had changes (increased QT interval) in their electrocardiography (ECG) at the time of admission.

\subsection{Treatment and Outcome}

The mean treatment time (naloxone infusion) in the patients was $57.3 \pm 2.3$ hours. Patients with apnea had significantly longer naloxone infusion than others ( $\mathrm{P}=$ 0.000 ). In $5.2 \%$ of the patients, symptoms recurred after discontinuation of naloxone. Two patients died as a result of methadone poisoning. One of them had cerebral hemorrhage and brain death and the other one had cardiopulmonary arrest at the time of admission.

\subsection{Complications in the Course of Hospitalization}

Twenty eight (48.3\%) children had pneumonia and aspiration pneumonia in the course of their hospitalization, as a result of loss of consciousness and apnea. The occurrence of pneumonia was significantly more frequent among patients with apnea $(\mathrm{P}=0.000)$. In the course of hospitalization one child had cerebral hemorrhage and brain death.

\section{Discussion}

Methadone is a synthetic long-acting opioid the use of which has been rising during the recent years (26-28). Poisoning by methadone is very dangerous and could have irreversible side effects. Hence, in most countries, in addition to putting warning labels on drug containers and keeping them away from children's reach, methadone is distributed in containers that children are not able to open (29).

Since 2003 methadone has been used as an alternative treatment for addiction and today there are 1500 methadone treatment centers in Iran. Unfortunately, in these centers, patients do not receive methadone syrup in proper and safe packaging, because these centers are required to return the standard bottles of methadone syrup to distributing institutions. On the other hand, without any training about how to maintain methadone and sufficient information about the risks of drug toxicity, especially in children, this dangerous substance is delivered to patients. In most cases, patients use mineral water bottles, soda bottles or other drug containers to receive methadone syrup from these centers and hold these bottles in refrigerator, as a result of which, methadone poisoning in children is increasing.

Farnaghi et al. (30) examined methadone poisoning among Iranian children in 2009. In his study the mean age of children was 55 months. The average age of children in the current study is 5.2 years (62.4 months). It should be considered that at these ages children are highly curious and also they have the ability to drink independently. As a result, more cases of methadone poisoning at this age is anticipated. In this study, the number of boys (56.9\%) was more than that of girls (43.1\%). In other studies, including the study by Farnaghi et al. (30), sex differences were not mentioned.

Based on the parents' report, on average 120 minutes after consuming methadone, the symptoms started to appear. The results of this study showed that the most common signs in children with methadone poisoning are drowsiness and miosis. The majority of children in the course of intoxication, progressively suffer from drowsiness and loss of consciousness. These results were consistent with those of previous studies, such as Farnaghi's et al. (30) in which drowsiness and miosis were reported to be the most common signs. Unfortunately, drowsiness and loss of consciousness are soundless symptoms and could not be detected soon by parents. Therefore, usually there is a long interval between children's exposure to methadone and the time when parents realize the poisoning. Based on the parents' reports, in this study children mostly felt sleepy at first and then the feeling of nausea and vomiting appeared. Over time, children become less conscious and problems like long pauses between breaths happen.

The classic triad of methadone poisoning in adults, including loss of consciousness (somnolence), ineffective respiration and miosis (12), were seen in 53\% of the subjects of the current study. Farnaghi also reported the frequency of $62 \%$ for this triad. On the other hand, Zamani et al. (31) observed this triad in only $25 \%$ of patients with opium poisoning. So the chance of this classic triad being caused by methadone poisoning is higher than by any other form of opioid poisoning.

The mean duration of treatment (naloxone infusion) was $57.3 \pm 2.3$ hours. After discontinuation of naloxone, in $5.2 \%$ of the patients naloxone infusion was restored because of recurring symptoms. The mean duration of naloxone infusion in Farnaghi's study (30) was 51 hours and the frequency of recurring symptoms after discontinuation of naloxone was reported to be $3 \%$. It should be considered that children with methadone poisoning should be monitored for 72 hours. On the other hand, the absence of symptoms cannot guarantee non-recurrence thereof. In this study, 8.6\% of patients had a seizure before treatment (naloxone) began and children who received naloxone had no seizure in the course of hospitalization. $6.2 \%$ of patients in Farnaghi's study also suffered from seizures. In the current study, only in $14 \%$ of the children increased QT interval was observed. In Farnaghi's study, $23.8 \%$ of children had increased QT interval. Thus, methadone toxicity could not be ruled out by normal ECG. 5.2\% of children had increased and 10.3\% decreased heart rate. Variable heart rate was also observed in other studies, including the study by Farnaghi in which $12.5 \%$ of the cases experienced increased heart rate and 6.2\% had decreased heart rate. However, in some studies only bradycardia was reported (32). In the present study, ataxia (6.9\%) and delirium (3.4\%) were observed, which is consistent with the results obtained by Farnaghi, where ataxia and delirium were reported in $6.1 \%$ and $3.1 \%$ of the subjects respectively. 


\subsection{Mortality}

Unfortunately two (3.4\%) children of 58 children passed away. One 6-year-old child was taken to the hospital with complete loss of consciousness and apnea due to the inadvertent intake of $100 \mathrm{mg}$ of methadone. At first, his parents refused to report methadone poisoning, but after several hours, they provided the physicians with the information. In the course of hospitalization, the child suffered from a cerebral hemorrhage and was transferred to the intensive care unit and connected to ventilator due to respiratory problems and had a severe pneumonia. Finally, he died a month later showing brain death.

Another child was two years old who inadvertently was fed with methadone which was kept in the bottle of acetaminophen syrup. The child had been left alone for hours before being taken to the hospital because his parents thought their child was asleep. At the time of admission the child was completely unconscious with apnea, unfortunately his resuscitation failed and the child died in the emergency department. Both children died because of a significant delay in receiving the required treatment, and this emphasizes the importance of quick transportation to medical centers. In a study in America, which was conducted on 30,000 cases from 2000 to 2008, 684 methadone poisoning deaths were reported. Twenty deaths occurred in children younger than 6 years old (33).

\subsection{Conclusions}

Keeping methadone in a standard bottle, away from children and warning methadone consumers about the dangerous side effects of methadone consumption and the symptoms of methadone poisoning in children may minimize the incidence of methadone poisoning and its complications in children.

\section{Acknowledgements}

The authors wish to acknowledge deputy of research of Kashan University of Medical Sciences for finanancial support of the study (Grant No: 9109).

\section{Authors' Contributions}

Mohammad Reza Sharif: Acquisition of data, Analysis and interpretation of data, Study supervision, Study concept and design, Statistical analysis, Saeed Nouri: Drafting of the manuscript, Critical revision of the manuscript for important intellectual content.

\section{References}

1. Gheshlaghi F, Piri-Ardakani MR, Yaraghi M, Shafiei F, Behjati M. Acute poisoning in children; a population study in isfahan, iran, 2008-2010. Iran J Pediatr. 2013;23(2):189-93.

2. Franklin RL, Rodgers GB. Unintentional child poisonings treated in United States hospital emergency departments: national esti- mates of incident cases, population-based poisoning rates, and product involvement. Pediatrics. 2008;122(6):1244-51.

3. Centers for Disease $C$, Prevention. Nonfatal, unintentional medication exposures among young children-United States, 20012003. MMWR Morb Mortal Wkly Rep. 2006;55(1):1-5.

4. Goldfrank L, Flomenbaum N, Lewin N. Toxiclogic Emergencies. 7th ed: McGraw-Hill; 2002.

5. Haddad M, Shannon W, Winchester F. Clinical management of poisoning and drug overdose. 3rd edPhiladelphia: Saunders; 2007.

6. Courtwright DT, Joseph H, Des Jarlais DC. Addicts who survived: an oral history of narcotic use in America,.Knoxville, TN: University of Tennessee Press; 1989.

7. Andima H, Krug D, Bergner L, Patrick S, Whitman S. A prevalence estimation model of narcotics addiction in New York City. Am J Epidemiol.1973;98(1):56-62.

8. Madden ME, Shapiro SL. The methadone epidemic: methadonerelated deaths on the rise in Vermont. Am J Forensic Med Pathol. 2011;32(2):131-5.

9. Aronow R, Brenner SL, Woolley PJ. An apparent epidemic: methadone poisoning in children. Clin Toxicol.1973;6(2):175-81.

10. Smialek JE, Monforte JR, Aronow R, Spitz WU. Methadone deaths in children. A continuing problem. JAMA. 1977;238(23):2516-7.

11. Watson WA, Litovitz TL, Rodgers GJ, Klein-Schwartz W, Reid N, Youniss J, et al. 2004 Annual report of the American Association of Poison Control Centers Toxic Exposure Surveillance System. Am J Emerg Med. 2005;23(5):589-666.

12. Wolff K. Characterization of methadone overdose: clinical considerations and the scientific evidence. Ther Drug Monit. 2002;24(4):457-70.

13. Li L, Levine B, Smialek JE. Fatal methadone poisoning in children: Maryland 1992-1996. Subst Use Misuse. 2000;35(9):1141-8.

14. Aronow R, Paul SD, Woolley PV. Childhood poisoning. An unfortunate consequence of methadone availability. JAMA. 1972; 219(3):321-4.

15. Jepsen F, Ryan M. Poisoning in children. Curr Paediatr. 2005; 15(7):563-8.

16. Cruciani RA. Methadone: to ECG or not to ECG...That is still the question. J Pain Symptom Manage. 2008;36(5):545-52.

17. Justo D. Methadone-induced long QT syndrome vs methadoneinduced torsades de pointes. Arch Intern Med. 2006;166(20):2288.

18. Ehret GB, Desmeules JA, Broers B. Methadone-associated long QT syndrome: improving pharmacotherapy for dependence on illegal opioids and lessons learned for pharmacology. Expert Opin Drug Saf. 2007;6(3):289-303.

19. Martin TC, Rocque MA. Accidental and non-accidental ingestion of methadone and buprenorphine in childhood: a single center experience, 1999-2009. Curr Drug Saf. 2011;6(1):12-6.

20. Blatman S. Methadone and children. Pediatrics. 1971;48(2):173-5.

21. DiMaio DJ, DiMaio T. Fatal methadone poisoning in children: report of four cases. J Forensic Sci.1973;18(2):130-4.

22. Binchy JM, Molyneux EM, Manning J. Accidental ingestion of methadone by children in Merseyside. BMJ. 1994; 308(6940):1335-6.

23. Schwab J, Caggiano AO. Pediatric methodone poisoning revisted. Clin Pediatr (Phila). 2001;40(2):119-20.

24. Nisse P, Cezard C, Peucelle D, Mathieu-Nolf M. [Accidental ingestion of methadone and buprenorphine by children. A case review of the Lille Poison Centre between 1995 and 2005]. Acta Clin Belg Suppl. 2006(1):37-40.

25. Kliegman RM, Stanton B, Geme J, Schor NF, Behrman RE. Nelson Textbook of Pediatrics. 19th edPhiladelphia: Saunders; 2011.

26. Lugo RA, Satterfield KL, Kern SE. Pharmacokinetics of methadone. J Pain Palliat Care Pharmacother. 2005;19(4):13-24

27. Fishman SM, Wilsey B, Mahajan G, Molina P. Methadone reincarnated: novel clinical applications with related concerns. Pain Med. 2002;3(4):339-48.

28. Toombs JD, Kral LA. Methadone treatment for pain states. Am Fam Physician. 2005;71(7):1353-8.

29. Gibson JC, Vulliamy A. Accidental methadone poisoning in children: a call for Canadian research action. Child Abuse Negl. 2010;34(8):553-4. 
30. Farnaghi F, Jafari N, Mehregan FF. Methadone Poisoning among Children Referred to Loghman-Hakim Hospital in 2009. Pajoohandeh J. 2012;16(6):299-303.

31. Zamani N, Sanaei-Zadeh H, Mostafazadeh B. Hallmarks of opium poisoning in infants and toddlers. Trop Doct. 2010;40(4):220-2.
32. Thanavaro KL, Thanavaro JL. Methadone-induced torsades de pointes: a twist of fate. Heart Lung. 2011;40(5):448-53.

33. Marcus SM. Accidental death from take home methadone maintenance doses: A report of a case and suggestions for prevention. Child Abuse Negl. 2011;35(1):1-2. 